\title{
Diversification of Higher Educational Institutions as a Factor of Sustainable Development of Education
}

\author{
Artur Gudmanian, Liubov Drotianko*, Serhii Sydorenko, Serhii Ordenov, and Nataliya \\ Chenbai \\ National Aviation University, Liubomyra Huzara ave., 1, 03058 Kyiv, Ukraine
}

\begin{abstract}
The article explores the processes of diversification of higher educational institutions in the context of the sustainable society, which poses specific requirements to the quality of training of new generations of professionals for economy, social sphere and culture. The authors believe that the co-evolution of higher education and the society of sustainable development may evolve along the line of horizontal diversification of higher educational institutions. In the framework of this type of diversification, many industry-specific institutions of higher education (academies, institutes, technological universities) launch educational programs beyond their specialized status and implement ICT education across all curricula. The authors emphasize that for higher education to be sustainable, besides being continuous, it needs to move in the direction of fundamentalization, universality, flexibility, informatization and increasing the role of the humanities. To be sustainable, higher education has to be innovative, based on a harmonious unity of teaching, research and industry-based training. Today, university curricula should be flexible and show a good balance between fundamental and applied disciplines, on the one hand, and so-called general disciplines, the humanities, social sciences and specialist, profession-specific disciplines on the other. The humanities must be granted a proper place in the content of university education, if we want universities to shape high cultural and moral values in their graduates.
\end{abstract}

\section{Introduction}

The present-day stage of the humanity's movement towards an increasingly globalized society is characterized by a dynamic nature of economic, social, political and cultural processes, which bring about essential transformation of all social practices, education being no exception. Social determination is a prerequisite not only for emergence of scientific knowledge, but also for its integration into culture and the social fabric, making the objectification of scientific knowledge possible only provided that the society shows proper regard for intellectual development. One of the core principles of the concept of

\footnotetext{
* Corresponding author: drotlg@nau.edu.ua
} 
sustainable development is the principle of society development based on the real potential of nature. A. Chumakov argues that in its interaction with nature human society cannot afford to be antagonistic within itself, and thus it has to create conditions for co-evolution of all the constituent elements of the social system. The scholar believes that in terms of social systems co-evolution becomes an essential means of achieving sustainable development of separate sociosystems and the world community as a whole [1, p. 419]. If that is so, it is vital that education re-orient itself towards realization of the sustainable development concept. In our opinion, one of the factors that can ensure co-evolution of the elements of the social system, and by doing so contribute to the implementation of the society's sustainable development program, is diversification of higher educational institutions (HEIs). A sociocultural analysis of the processes of diversification of HEIs necessarily presupposes an analysis of the current system of higher education as a whole, as the society is transferring to sustainable development - a new stage which poses new challenges to the quality of training professionals for all branches of economy, social sphere and culture.

\section{Materials and Methods}

In view of the deep interaction of different cultures, both in the historical and modern perspectives, which naturally involves educational ideas, methods and systems existing in societies across the globe, we believe that while analyzing diversification in various systems of higher education and making predictions about its future, it is expedient to employ comparative and sociocultural approaches.

\section{Results and Discussion}

A study of diversification of HEIs in the context of shaping the society of sustainable development, in our opinion, should be based on a comprehensive analysis of the sociocultural situation in the present-day globalized society, as education is an essential attribute of this society. U. Teichler in his work "Diversity and Diversification of Higher Education: Trends, Challenges and Policies" provides valuable insights into the specificity of higher education diversification and argues that "diversity is among the most popular and controversial issues in higher education policy because policies in this domain are widely viewed as being very powerful" [2, p. 15]. For very practical reasons, university education today has to anticipate the challenges which society will pose to its members in the near future and offer adequate responses and solutions to them. At the same time, we cannot properly understand the specific global transformations of the present-day higher education without proper regard for the fundamental principles of its classical form.

The core idea of the classical university education was formulated by W. von Humboldt, who believed that higher education must combine research and study. Only teaching based on research can instill in students a constant internal need to pursue research activities. This approach laid the foundation of the classical concept of university education, which emphasizes that education must embrace fundamental knowledge which is being discovered by the cutting-edge scientific research. Humboldt's main idea was that a higher educational institution should not only perform educational functions, but also be a part of research infrastructure. The major mission of a university is to engage young people in research, introduce them to its nature and fundamental principles.

Since the epoch of Enlightenment, science has been asserting itself through university education. The organic combination of research aimed at production of new knowledge and the delivery of this knowledge has always been the core of university education in modern 
history. The fathers of modern university education W. von Humboldt and J. H. Newman believed that universities not only expand students' knowledge but also train their intellect. J. H. Newman and his followers insisted that universities should be above people's transient needs and emphasized the importance of humanistic education of students. The major axiological pillars of classical university education were knowledge as its goal, intellectuality and intelligence. In a classical university, scientific research has always been associated not only with growth of new knowledge, but also with the process of its mastery, intellectual cultivation, based on students' broad education in the humanities, development of their mind and personal qualities as the final aim of university education.

There is no single answer to the question about the essence and objectives of higher education, as its existence is rooted in a complex variety of society's needs. At the outset, universities were meant to train political elite with a broad outlook, so the curriculum was defined by fundamental natural sciences, social sciences and the humanities. With time, the rapid progress of industrial production called for specialists with various specialist degrees in specific branches of economy. This, in turn, brought about a utilitarian approach to the essence and mission of higher education in the context of scientific and technological revolution, especially since the second half of the previous century.

Narrow specialization of university education has been opposed by the world's leading scientists. In the middle of the twentieth century, W. Heisenberg debated with those scientists who believed that in order to be successful, one has to master practical skills which are essential in modern life: new languages, technological methods, management and accounts, whereas the humanities become only a decoration, a luxury affordable to those few whose destiny did not force them to struggle for their place under the sun [3, p. 41]. W. Heisenberg argued that the person who wants to get to the core of their occupation, be it technology or medicine, sooner or later will go back to the invaluable sources of antiquity and benefit immensely by learning from the Greeks how to think radically and define essential problems. W. Heisenberg used to refer to his personal experience of studying at the University of Göttingen.

The narrow, utilitarian concept of education had its roots in the capitalist production, which viewed all things, including knowledge, as resources needed for continuous development embodied in the growth of capital. This inevitably made a very special impact on the content of university education in many developed countries, determining its technology-centered nature, which neglected the humanities. No doubt, such developments in the university education were conditioned by the economic factor, which became so dominant in all spheres of life that "...in the system of restrictions absence, the influence of market mechanisms determines the exploitation and neglect of social needs" [4]. It was economic expediency that promoted commercialization of education and science, which met the expectations of the increasingly globalized capitalism. However, it is obvious that the status of university education and science cannot be reduced to the vulgar utilitarianism of economic expediency.

We believe that the popular identification of science with innovation is fallacious, as the task of science is to establish objectively existing regularities, properties and phenomena of the world, which have fundamental, not purely applied, nature. Such broad mission of science makes it possible to use results of scientific research in various spheres of life, addressing a vast range of practical problems. In this connection, $\mathrm{Yu}$. Kostiuchenko argues that when science in its broad meaning is required to produce applied results, this is not "pure science", but rather R\&D. As for innovations and startups, they are nothing but business undertakings aimed at creating instruments for making profits in a certain social and economic environment. Scientists cannot be required to produce innovations and startups. Startups are developed by students, who do not need much science to do that. What they need is a certain environment, certain social and economic conditions and ready 
technologies based on already developed techniques [5]. Thus, the major problem of today's education, in our opinion, is its utilitarian commercialization, which attempts to reduce education to the delivery of a certain amount of information, whose volume and content are tailored to the volatile job market.

E. Fromm wrote that the contemporary system of education in most cases teaches people to obtain knowledge as a kind of property, an asset that stands in proportion to that financial and social status which this knowledge may bring them in the future. Minimum knowledge is enough for most people to be able to perform their job duties [6]. The specialization tendency, which separated people from natural entirety and broke their ties with the surrounding, brought about a dramatic change in the understanding of education. The results are seen in neoliberal reforms of higher education in many countries [7]. If earlier the classical model of university education combined teaching with comprehensive personal development and the shaping of the person's values and views, acting not only as a channel of knowledge transfer, but also as an instrument of socialization and cultural development, today the person appears to be auxiliary in the global economy, which does not care about humanistic values, socialization and instilling high moral values. As a result, university curricula have been getting rid of liberal arts, so-called general disciplines, and the process of education has been losing its axiological component and social significance on the global scale.

In this context, we would like to refer to the philosopher Kato Yasushi, who points out that Japan is working on government-funded science development programs aimed at production of economic values and formation of models of interaction between science, market and technologies. Every four years the development of Japanese science is determined by "Science and Technology Basic Plan" (STBP) adopted by the Ministry of Education. Currently, Japan is implementing the fifth "Basic Plan". The researcher states that the concept of "innovation" dominates modern society, so every new adopted "Basic Plan" makes an increasingly heavier emphasis on science and technology development aspects, whereas the humanities and social sciences are being further neglected. As a result, the scientific discourse is losing the general perspective of "human wisdom", or "knowledge for mankind". In addition, the status of fundamental research is changing, as it is being reduced to "short-term solution-finding research". Such situation is a fertile soil for initiatives aimed at a drastic reform of universities, including the closure of faculties for the humanities and social sciences. Kato Yasushi explains that "according to the 5th STBP, social problems are solved by science-based technologies", and "innovation through science-based technology" turns out to mean that social change is equivalent to the progress of science-based technology" [8, p.13]. The scholar points out that the poor state of the humanities against the background of the dominating "innovations" concept is not a uniquely Japanese phenomenon. It is rather a menacing symptom which has global manifestations. These developments are quite in harmony with "Horizon 2020", a massive research and innovation program adopted by the EU in January 2014, whose aim is to connect the results of research with innovations, economic growth and employment of the population.

We believe that such policy threatens comprehensive harmonious development of fundamental knowledge and does not conform to the key principles of society's sustainable development embodied in the UNECE Strategy for Education for Sustainable Development. The Strategy states that "education should retain its traditional focus on individual subjects and at the same time open the door to multi- and inter-disciplinary examination of real-life situations" [9, p. 18]. It is important to remember that it is interdisciplinary research that to a large extent defines the development of modern science. D. Weidne argues, "Here, diversity proved fruitful in bringing forth new forms of knowledge amongst them a kind of knowledge for which diversity has become an essential epistemic 
quality" [10, p. 50]. It appears that diversification can step in onto the scene as an essentially novel instrument of acquiring knowledge in university education.

The unity of the humanization principle and the principle of the fundamental nature of university education has always acted as a special mechanism of the realization of the humanistic potential of university education. V. Onoprienko argues that the humanistic potential of fundamental knowledge in university education manifests itself through the ability of this knowledge to play a leading role in the creation of the person's system of core beliefs and shape the person's biocentric and ethic views. The realization of the principle of the fundamental nature of university education gives the possibility to bridge the gap between the humanities and natural sciences, which arose historically, and forms a holistic image of the world and culture [11, p. 98]. Orientation of the fundamental sciences towards the knowledge about properties, structure and dependencies of the studied objects and phenomena defines the major role these sciences play in shaping the person's worldview. Learning fundamental sciences at the university, students build a holistic and consistent understanding of the reality, which makes it possible to naturally combine the functions of education with students' personal development, contributes to the formation of a theory-oriented type of scientific thinking and creates an intellectual basis for students' self-development.

In our opinion, ills of modern university education, seen in its unnecessary marketization accompanied by compromising its fundamental character and humanistic nature, can be cured by increasing its fundamental content and simultaneous diversification. Marco Porzionato and Federica de Marco, the authors of "Excellence and Diversification of Higher Education Institutions' Missions", underline that "there is an increasing awareness of the fact that [university] rankings ... should reflect different behaviours of universities, and in particular the different ability among universities to comply and to cope with sustainability issues" [12, p. 289]. Diversification is commonly understood as vertical differentiation, which is characterized by such aspects as differences in degrees conferred (Bachelor's, Master's and PhD programs), focus of some HEIs on teaching and others on research, existence of top elite-training universities, such as Oxford and Cambridge, which educate leaders for public administration and business. As for horizontal diversification, it tends to develop spontaneously and may result from the increase in the number of HEIs of the same level, or emergence of more prestigious HEIs among same-level institutions, or appearance of "fashionable" specialties on the educational market, which are in high demand among school-leavers. We believe that it is along this line of horizontal diversification that the co-evolution of higher education and the society of sustainable development can take place.

We see this type of diversification going on in Russia, Ukraine and other post-Soviet countries. In response to demands of the time and society, many industry-specific HEIs (academies, institutes, technological universities) are launching programs in the humanities, opening departments of the humanities and social sciences and introducing ICT across all curricula, which makes their initial industry-specific profile largely nominal.

For example, National Aviation University, Ukraine, did not have faculties with "nonaviation" majors until the late 1990s. In its structure, the university had departments which taught general disciplines, the humanities and social sciences to all students. In the early 2000 s, the university for the first time opened faculties which offered "non-aviation" majors, i.e. programs not directly connected with aviation industry (Table 1). 
Table 1. Emergence of "non-aviation" educational divisions at the National Aviation University, Ukraine

\begin{tabular}{|l|l|}
\hline \multicolumn{1}{|c|}{ 1990s } \\
$\begin{array}{l}\text { Departments of the National Aviation University, } \\
\text { Ukraine, which taught general disciplines, the } \\
\text { humanities and social sciences }\end{array}$ & $\begin{array}{l}\text { 2020 } \\
\text { Non-aviation faculties at the National } \\
\text { Aviation University, Ukraine }\end{array}$ \\
\hline Higher Mathematics Department & $\begin{array}{l}\text { Faculty of Cybersecurity, Computer and } \\
\text { Software Engineering }\end{array}$ \\
\hline Job Safety and Environment Protection Department & $\begin{array}{l}\text { Faculty of Ecological Safety, Engineering and } \\
\text { Technologies }\end{array}$ \\
\hline Department of Economics & $\begin{array}{l}\text { Faculty of Economics and Business } \\
\text { Administration }\end{array}$ \\
\hline $\begin{array}{l}\text { Foreign Languages Department } \\
\text { Department of the History of Ukraine } \\
\text { Philosophy Department }\end{array}$ & $\begin{array}{l}\text { Faculty of Linguistics and Social } \\
\text { Communications }\end{array}$ \\
\hline Culture and Law Department & Faculty of International Relations \\
\cline { 2 - 2 } & Faculty of Law \\
\hline
\end{tabular}

Appearance of new, "non-aviation" faculties and departments at the National Aviation University over the recent decades is a vivid manifestation of internal diversification which has been going on in the university structure and in the content of the educational programs. Some departments that had been earlier teaching so-called general disciplines for various majors, launched their own training programs. For example, law had been taught in the university long before 2000, when the program in law enrolled its first students. Currently, the university's Education Quality Department is continuously monitoring the effectiveness of the educational programs offered by the university to provide a timely response to the demands of the society in terms of opening new training programs and optimizing the existing ones.

Similar diversification is happening in the HEIs specializing in the humanities, which are launching majors in technology, above all connected with computer technology and systems.

Besides these types of diversification, HEIs vary according to the sources of funding public ones are funded mainly from the national budget, and private ones mainly depend on tuition fees. Private HEIs emerged in response to the society's demand for a wider scope of educational services and as a result of insufficient public funding of higher education. In Ukraine and other post-Soviet countries, public HEIs also charge tuition fees to a substantial share of their students.

In the information society, which is globalizing all spheres of our life, we are witnessing appearance of joint European and transatlantic international organizations which are increasingly defining not only economy, politics, social life, but also national cultures, nature of education and methods of knowledge transfer. The very functioning of HEIs is becoming more and more subject to the common goals and prospects of the social system. Such situation inevitably confines higher education to the context of utilitarian approach. This fact was vividly illustrated by Jean-François Lyotard in the case of legitimation of university teaching grounded on its effectiveness. The scholar argues that when effectiveness of a social system becomes the criterion of its justification, i.e. a society subjects itself to the systems theory, higher education begins to be regarded only as a subsystem of the social system, viewed from the perspective of effectiveness. The effectiveness expected from higher education is supposed to consist in the contribution the educational subsystem makes to the overall effectiveness of the whole social system [13].

Such approach determines the structure of HEIs, the way courses are taught, the very list of these courses, which are expected to ensure the nation's success in the global 
economic competition and are correspondingly adjusted depending on what the country can profitably "sell" on the world market. According to J.-F. Lyotard, in such conditions, all disciplines that go under the umbrella of "telematics" (informatics, cybernetics, linguistics, mathematics, logic, etc.) have to be seen as education priorities, as they will determine and accelerate the progress of research in other fields of knowledge [14].

However, the goal of education in the information age should be the priority development of human values, hence, the focus should be made on forward-looking, cutting-edge education, which can satisfy the need in the knowledge which does not exist yet. Such ambitious goals call for fundamentalization of education, adjustment, on the one hand, of fundamental and applied sciences to the changes in the higher education, and on the other, incorporation of the latest scientific achievements in the educational process. Fundamentalization is believed to be one of the top-priority strategic directions in higher education reform, involving a clear understanding of what is of primary importance and is directly connected to the solution of specific social problems and what is of secondary significance. The fundamental nature of higher education can only be provided if educational institutions not only deliver to their students the full amount of the required knowledge, but also develop their ability to pursue intellectual research. Such approach seems to be most effective in the process of sustainable development of education, as the mission of universities in a sustainable society is not so much to deliver knowledge, which quickly becomes obsolete, but rather to help students acquire basic competencies, which will allow them to get knowledge on their own. Thus, it is fundamental education combined with research that scholars regard as the factor of positive change in all spheres of social life expected to take place in a society of sustainable development.

An important role in this process belongs to innovative technologies in education. Using ICT, students learn to find necessary scientific information, master new languages, including artificial ones. Educational information and communication technologies perform not only cognitive, but also sociocultural functions, as network communication requires that its participants have corresponding language skills and adhere to the commonly recognized norms of behaviour.

There is no doubt that new possibilities and easy access to information affect the speed of teaching and learning. There is an opinion that today students need less time to assimilate the material delivered at lectures. But this seems to be rather a superficial view. Actually, no new technologies currently used in education can notably accelerate cognition processes, the speed of the human brain. Victor Sadovnichy, rector of Lomonosov Moscow State University, argues that education is a creative process, which resembles the scientific method. It requires from students independent intellectual creativity, which cannot be accelerated by any information technologies [14].

In support of the above-mentioned, it is necessary to add that operating databanks in no way belittles the role of the teacher in the educational process, as the interpersonal communication cannot be replaced by impersonal information, however novel and exciting it may be. Surely, in the information age, the focus in education shifts onto students' independent study, which poses new challenges to university academics. Their role is now increasingly seen as that of a guide and advisor who can help students to orient themselves in the information flow and teach them to transform information into knowledge. In particular, such role of the university teaching staff has come to the forefront during COVID-19 pandemic.

In the present-day situation, universities and other HEIs are losing the features of Humboldtian education, which aimed at the achievement of the ideal of personal freedom. Transfer of knowledge is no longer perceived as a process directed at forming the elite able to lead the nation to freedom - it serves the system by training those who can competently fit in practical positions required by the agencies of the given social system. Such 
transformation inevitably results in the universities training the hidden unemployed, especially in the field of the humanities, as holders of such diplomas by far outnumber available job vacancies.

The modern system of higher education can also be diversified according to the kinds of knowledge, namely: propositional or theoretical knowledge; procedural or practical knowledge; and knowledge by acquaintance. There is a visible tendency today to give precedence to theoretical knowledge over practical knowledge, whereas knowledge by acquaintance is often ignored in epistemological discussions. In practice, the interrelation between these three kinds of knowledge is realized through interpretation of theories, methods and prescriptions via familiarization. At the same time, practical knowledge is gained through participation in activity, which, in its turn, requires constant broadening of theoretical knowledge to update personal skills. Knowledge by acquaintance is vital in the process of acquiring competencies, without which theoretical knowledge loses its value.

Summing up, the society of sustainable development needs people who are able to adjust to our fast-changing world, have broad knowledge, skills in continuous learning and a digital-era intellect. Its peculiarity is the unification of the scientists' efforts not only in related, but, at first glance, incommensurable sciences: natural and humanitarian; technical and humanitarian; natural, humanitarian and technical based on new mathematical theories [15]. For higher education to be sustainable, besides being continuous, it needs to develop towards fundamentalization, universality, greater flexibility, an increasing role of the humanities, informatization, innovative character and combination of learning, research and industry-based training. Modern universities should become centers of such research- and industry-driven education.

Educational policy in every country is expected to give answers to the following questions: how well does the existing education system meet the sustainable development requirements? does it yield the expected results? what criteria should be used to measure its effectiveness in a sustainable society? etc. All this calls for an objective assessment of the current state of higher education, and diversification of higher educational institutions promises good prospects in addressing the existing challenges.

\section{Conclusions}

The conducted analysis of various approaches to diversification in higher education shows that there exists no ideal proportion of sciences, natural sciences and the humanities which could be optimal for all HEIs and all groups of related majors. University curricula have to be flexible, on the one hand, in terms of reacting to the cutting-edge research in the field, and on the other, in terms of responding to the demands of society, which, as we have seen, poses new challenges before higher education at each stage of its development. It is important that curricula ensure a good balance between fundamental and applied disciplines, and also have room for so-called general disciplines, social sciences, and the humanities, which shape personal qualities of future professionals, their worldview and raise their cultural level. Naturally, the specialization of a HEI, which trains specialists for a specific industry, needs to find an adequate reflection in its educational programs. It should also feature in syllabi of various disciplines. Here, many constructive solutions in curriculum and syllabus design may be offered by philosophy of education.

As for the specificity of diversification of HEIs in shaping the society of sustainable development, we should not limit it only to the diversity of majors, departments, faculties and institutes within existing universities and new emerging specialized institutions. Diversification should embrace essential changes in curricula and syllabi, implementation of information and communication technologies in teaching even most "traditional" disciplines. Computerization and informatization of teaching and learning mean a transfer 
to such forms of obtaining, processing and assimilation of innovative scientific information, which could enable students to acquire larger amounts of information in a shorter time. The urgency of these issues has been convincingly proved during the COVID-19 pandemic, which made diversification of teaching and learning the top agenda of today's higher education.

\section{References}

1. A. Chumakov, Metaphysics of globalization. Cultural and civilizational context (2017)

2. U. Teichler, Educational Studies Moscow, 1, 14 (2015)

3. W. Heisenberg, Steps beyond the horizon (1987)

4. A. Gudmanian, L. Drotianko, O. Shostak, H. Kleshnia, S. Ordenov, E3S Web of Conferences, 175 (2020)

5. Yu. Kostiuchenko, Day, 30 August (2018)

6. E. Fromm, To have or to be? (2014)

7. J. Horne, British Journal of Educational Studies (2020)

8. K. Yasushi, Tetsugaku, International Journal of the Philosophical Association of Japan, 1, 8 (2017)

9. The UNECE Strategy for Education for Sustainable Development

10. D. Weidne, Conference Horizons for Social Sciences and Humanities, 49 (2013)

11. V. Onoprienko, Proceedings of the National Aviation University. Series: Philosophy. Cultural Studies, 1, 97 (2013)

12. M. Porzionato, F. Marco, The European Higher Education Area Between Critical Reflections and Future Policies, 285 (2015)

13. J.-F. Lyotard, The postmodern condition (2013)

14. V. Sadovnichy, Moscow University Bulletin, 20, 15 (2006)

15. L. Drotianko, O. Shostak, M. Abysova, N. Chenbai, E3S Web Conf., 157 (2020) 